\title{
PERBANDINGAN INVESTASI PADA MATA UANG DOLAR AMERIKA (USD) DAN YEN JEPANG (JPY) DENGAN MODEL ARIMA DAN GARCH
}

\author{
DEGIKA WIDYA TAMA, MAIYASTRI, YUDIANTRI ASDI \\ Program Studi Matematika, \\ Fakultas Matematika dan Ilmu Pengetahuan Alam, Universitas Andalas, \\ Kampus UNAND Limau Manis Padang, Indonesia, \\ degikawidyatama360@yahoo.com
}

\begin{abstract}
Abstrak. Nilai tukar mata uang merupakan hal penting yang harus diperhatikan seseorang apabila akan melakukan investasi. Namun pada kenyataannya nilai tukar mata uang cenderung berubah-ubah dari waktu ke waktu. Naik turunnya nilai tukar mata uang menunjukkan besarnya volatilitas. Data nilai tukar mata uang dapat dimodelkan dengan pemodelan deret waktu. Salah satu model yang sering digunakan yaitu model ARIMA. Untuk memodelkan tingkat volatilitas digunakan model GARCH, kemudian dilakukan perhitungan untuk menentukan resiko kerugian maksimum dengan metode Value at Risk. Pada penelitian ini data nilai tukar/kurs yang digunakan adalah kurs Dolar Amerika (USD) dan Yen Jepang (JPY) terhadap Rupiah. Dari hasil penelitian diperoleh bahwa model ARIMA terbaik untuk kurs USD yaitu ARIMA $(0,1,1)$ dan ARIMA terbaik untuk kurs JPY adalah ARIMA $(2,1,2)$. Dengan model ARIMA terbaik diperoleh nilai peramalan untuk masing-masing kurs, dimana peramalan yang terbesar untuk data sebenarnya adalah kurs USD. Untuk pemodelan volatilitas dengan model GARCH dengan menggunakan data return diperoleh model terbaik untuk kurs USD yaitu GARCH $(2,1)$ dan GARCH $(1,1)$ untuk kurs JPY. Dari model GARCH terbaik diperoleh ramalan return dan volatilitas yang akan digunakan dalam perhitungan Value at Risk. Dari pehitungan Value at Risk diperoleh resiko terkecil adalah mata uang USD. Sehingga investasi terbaik dilakukan pada mata uang Dolar Amerika (USD).
\end{abstract}

Kata Kunci: Nilai tukar, ARIMA, return, GARCH, volatilitas, Value at Risk

\section{Pendahuluan}

Uang merupakan salah satu hal penting dalam kegiatan perekonomian di seluruh dunia. Pertukaran antara dua mata uang yang berbeda disebut kurs atau nilai tukar. Nilai tukar mata uang cenderung berubah seiring waktu, Naik turunnya nilai tukar mata uang menunjukkan besarnya volatilitas yang terjadi. Volatilitas yang semakin tinggi menunjukkan pergerakan kurs atau nilai tukar yang semakin besar.

Nilai tukar mata uang dan tingkat volatilitas dapat dianalisis dengan menggunakan analisis deret waktu. Model yang digunakan dalam pemodelan deret waktu yaitu model Autoregressive Integrated Moving Average (ARIMA). Memodelkan tingkat fluktuasinya (volatilitas) digunakan model Generalized Autoregressive Conditional Heteroscedasticity (GARCH) dan untuk melakukan pengukuran resiko terhadap kemungkinan kerugian yang akan dialami digunakan Value at Risk (VaR). Value at Risk merupakan metode perhitungan untuk menentukan resiko kerugian 
maksimum yang dapat terjadi. Pada penelitian ini data nilai tukar/kurs yang digunakan adalah kurs Dolar Amerika (USD) dan Yen Jepang (JPY) terhadap Rupiah.

\section{Landasan Teori}

Berikut adalah beberapa model deret waktu yang dibahas dalam penelitian ini.

(1) Model Autoregressive (AR)

Bentuk umum model MA dengan orde $p$ adalah sebagai berikut:

$X_{t}=\phi_{1} X_{t-1}+\phi_{2} X_{t-2}+\cdots+\phi_{p} X_{t-p}$

(2) Model Moving Average (MA)

Bentuk umum model MA dengan orde $q$ adalah sebagai berikut:

$X_{t}=\epsilon_{t}-\theta_{1} \epsilon_{t-1}-\theta_{2} \epsilon_{t-2}-\cdots-\theta_{q} \epsilon_{t-q}$

(3) Model Autoregressive Moving Average (ARMA)

Bentuk umum model ARMA dengan orde dari AR adalah $p$ dan orde dari MA adalah $q$ dinyatakan sebagai berikut:

$$
X_{t}=\phi_{1} X_{t-1}+\phi_{2} X_{t-2}+\cdots+\phi_{p} X_{t-p}+\epsilon_{t}-\theta_{1} \epsilon_{t-1}-\cdots-\theta_{2} \epsilon_{t-2}-\theta_{q} \epsilon_{t-q}
$$

(4) Model Autoregressive Integrated Moving Average (ARIMA)

Bentuk umum model ARIMA dinyatakan sebagai berikut:

$$
\nabla^{d} X_{t}=\phi_{1} X_{t-1}+\phi_{2} X_{t-2}+\cdots+\phi_{p} X_{t-p}+\epsilon_{t}-\theta_{1} \epsilon_{t-1}-\cdots-\theta_{2} \epsilon_{t-2}-\theta_{q} \epsilon_{t-q}
$$

Return yaitu tingkat keuntungan yang diperoleh investor. Cara menghitung return yaitu:

$$
R_{t}=\ln \left(\frac{X_{t}}{X_{t-1}}\right) .
$$

Volatilitas berasal dari kata volatile, yang mengacu pada kondisi yang berarti tidak stabil, cenderung bervariasi dan sulit diperkirakan. Volatilitas digambarkan dengan ragam yang selalu berubah atau datanya heteroskedastisitas. Karena kondisi ini Engle mengembangkan model Autoregressive Conditional Heteroscedasticity (ARCH) dan disempurnakan lagi oleh Tim Bollerslev menjadi model Generalized Autoregressive Conditional Heteroscedasticity (GARCH).

Secara umum, model $\mathrm{ARCH}(\mathrm{q})$ dapat dinyatakan sebagai berikut :

$$
\sigma_{t}^{2}=\alpha_{0}+\alpha_{1} \epsilon_{t-1}^{2}+\cdots+\alpha_{q} \epsilon_{t-q}^{q}
$$

dengan $\alpha_{0}>0, \alpha_{i} \geq 0$.

Bentuk umum model $\operatorname{GARCH}(p, q)$

$$
\sigma_{t}^{2}=\alpha_{0}+\alpha_{1} \epsilon_{t-1}^{2}+\cdots+\alpha_{q} \epsilon_{t-q}^{q}+\beta_{1} \sigma_{t-1}^{2}+\cdots+\beta_{p} \sigma_{t-p}^{2}
$$

dengan $p \geq 0, q>0, \alpha_{0}>0, \alpha_{i} \geq 0, i=1,2, \cdots, q, \beta_{j} \geq 0, j=1,2, \cdots, p$, dan $\left(\sum \alpha_{i}+\sum \beta_{j}\right)<1$

Perhitungan Value at Risk pada tingkat kepercayaan sebesar $(1-\alpha)$ sebagai berikut

$$
\operatorname{VaR}=\left[\hat{r}_{t}-z_{\alpha} \hat{\sigma}_{t}\right] \cdot W_{0}
$$




\section{Data dan Hasil}

(1) Pemodelan kurs USD dan JPY dengan Model ARIMA.

Data nilai tukar rupiah yang dianalisis terdiri dari dua mata uang yang dipilih yaitu mata uang Dolar Amerika (USD) dan mata uang Yen Jepang (JPY) periode tanggal 1 Juli 2013 sampai 21 Juni 2016 berupa data harian dengan data sebanyak 729 , berikut plot datanya sebagai berikut.

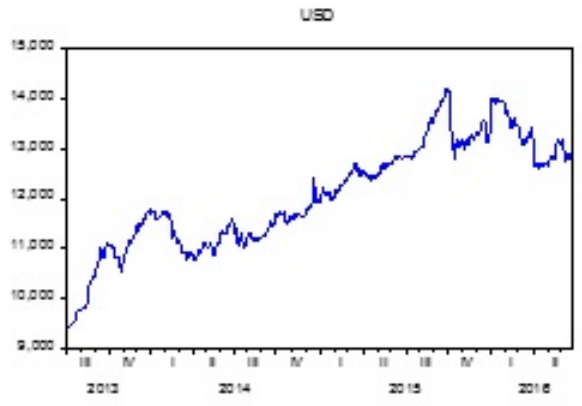

Gambar 1. Plot data kursUSD

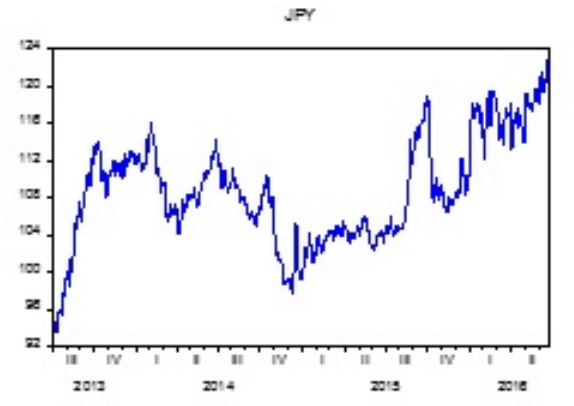

Gambar 2. Plot data kursJPY

Dari plot data pada Gambar 1 dan Gambar 2 diperoleh plot data USD membentuk tren positif sedangkan plot data JPY membentuk plot tidak beraturan. Dari gambar juga dapat dilihat bahwa data tidak berfluktuasi disekitar nilai tengah dan ragam sehingga disimpulkan bahwa data tidak stasioner. karena data belum stasioner maka dilakukan proses pembedaan (differencing), dengan plot sebagai berikut.
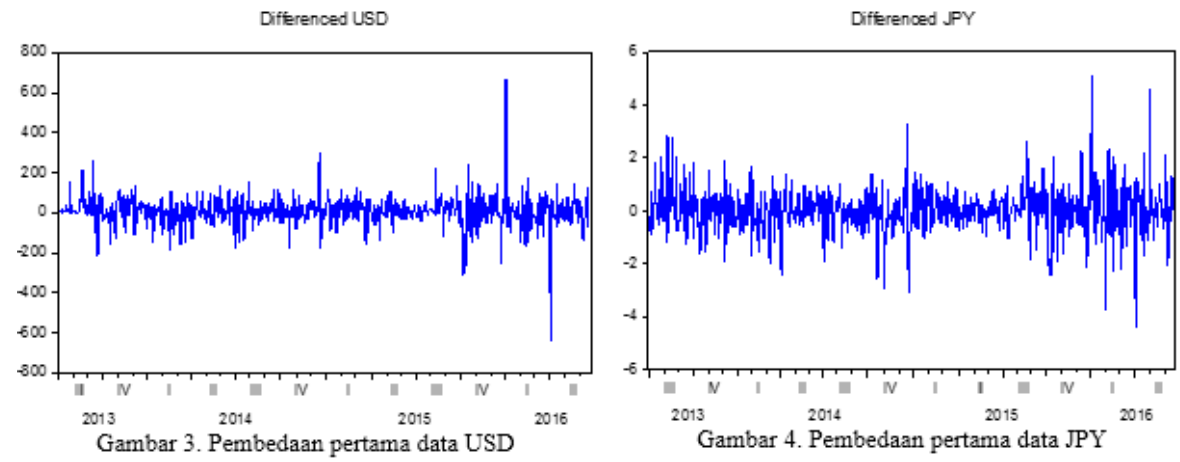

Berdasarkan Gambar 3 dan Gambar 4 dapat dilihat bahwa data berfluktuasi pada suatu nilai konstan. Sehingga secara grafis hal ini menunjukkan bahwa data telah stasioner. Untuk membuktikannya dilakukan uji ADF terhadap data yang telah dilakukan pembedaan pertama. Diperoleh nilai ADF untuk USD yaitu -24.40975 lebih kecil dari nilai kritisnya yaitu -2.568828 . Untuk nilai ADF untuk JPY diperoleh nilai - 25.80472 lebih kecil dari nilai kritisnya yaitu -2.568828, dengan demikian dapat disimpulkan data telah stasioner.

Selanjutnya akan diidentifikasi model $\operatorname{ARIMA}(p, 1, q)$ yang cocok menggunakan korelogram. Berdasarkan korelogram baik ACF dan PACF pada 
data pembedaan pertama kurs USD menunjukkan penurunan secara bertahap menuju nol setelah lag 1 . Oleh karena itu, kemungkinan model untuk kurs USD terhadap Rupiah adalah ARIMA $(1,1,0)$, ARIMA $(0,1,1), \operatorname{ARIMA}(1,1,1)$. Pada korelogram pembedaan pertama kurs JPY baik ACF dan PACF menunjukkan penurunan secara bertahap menuju nol setelah lag 5 . Oleh karena itu, kemungkinan model diantaranya yaitu ARIMA (1,1,1), ARIMA $(2,1,2)$, ARIMA $(3,1,3)$, ARIMA $(4,1,4)$ dan ARIMA $(5,1,5)$.

Langkah selanjutnya adalah mengestimasi parameter model. Berikut adalah hasil estimasi model rataan kurs USD dan kurs JPY terhadap Rupiah.

\begin{tabular}{|c|c|c|c|}
\hline & $\operatorname{ARIMA}(1,1,1)$ & $\operatorname{ARIMA}(1,1,0)$ & ARIMA $(0,1,1)$ \\
\hline$\phi_{1}$ & $0.308504(0.3598)$ & $0.100998(0.0064)$ & \\
\hline$\theta_{1}$ & $-0.210340(0.5435)$ & & $0.097978(0.0081)$ \\
\hline AIC & 11.50326 & 11.50085 & 11.49982 \\
\hline BIC & 11.51888 & 11.50716 & 11.50612 \\
\hline logLikelihood & -4179.434 & -4179.559 & -4184.993 \\
\hline peringkat & Tidak signifikan pada $\phi_{1}$ dan $\theta_{1}$ & 2 & 1 \\
\hline
\end{tabular}

Dari Tabel 1 diperoleh model terbaik untuk kurs Dolar Amerika (USD) terhadap Rupiah ARIMA $(0,1,1)$ yaitu

$$
\nabla^{1} X_{t}=0.097978 \varepsilon_{t-1}+\varepsilon_{t} .
$$

Tabel 2. Estimasi model Rataan Kurs Yen Jepang (JPY) terhadap Rupiah

\begin{tabular}{cclcc}
\multicolumn{6}{c}{ Tabel 2. Estimasi model Rataan Kurs Yen Jepang (JPY) terhadap Rupiah } \\
\hline \multicolumn{7}{c}{ ARIMA $(2,1,2)$} & ARIMA $(3,1,3)$ & ARIMA $(4,1,4)$ & ARIMA $(5,1,5)$ \\
\hline$\phi_{1}$ & $-1.394257(0.0000)$ & $-2.066937(0.0000)$ & $0.202745(0.0000)$ & $1.147772(0.0000)$ \\
\hline$\theta_{1}$ & $1.421959(0.0000)$ & $2.122311(0.0000)$ & $-0.183189(0.0000)$ & $-1.130301(0.0000)$ \\
\hline$\phi_{2}$ & $-0.957028(0.0000)$ & $-1.888661(0.0000)$ & $0.199778(0.0000)$ & $0.083431(0.0006)$ \\
\hline$\theta_{2}$ & $0.990787(0.0000)$ & $1.984738(0.0000)$ & $-0.200513(0.0000)$ & $-0.110301(0.0000)$ \\
\hline$\phi_{3}$ & & $-0.632510(0.0356)$ & $0.173260(0.0000)$ & $-0.125521(0.0000)$ \\
\hline$\theta_{3}$ & $0.689365(0.0204)$ & $-0.177687(0.0000)$ & $0.105969(0.0000)$ \\
\hline$\phi_{4}$ & & $-0.969280(0.0000)$ & $-1.070776(0.0000)$ \\
\hline$\theta_{4}$ & & $0.987487(0.0000)$ & $1.125215(0.0000)$ \\
\hline$\phi_{5}$ & & & & $0.924649(0.0000)$ \\
\hline$\theta_{5}$ & & & & $-0.968164(0.0000)$ \\
\hline AIC & 2.570769 & 2.575434 & 2.577347 & 2.577119 \\
\hline BIC & 2.596045 & 2.613389 & 2.628008 & 2.630514 \\
\hline logLikelihood & -929.1891 & -927.5950 & -924.9996 & -918.0136 \\
\hline peringkat & 1 & 2 & 3 & 4 \\
\hline
\end{tabular}

Dari Tabel 2 diperoleh model terbaik untuk kurs Yen Jepang JPY terhadap Rupiah ARIMA $(2,1,2)$ yaitu

$$
\nabla^{1} X_{t}=-1.394257 X_{t-1}-0.957028 X_{t-2}+1.421959 \varepsilon_{t-1}+0.990787 \varepsilon_{t-2}+\varepsilon_{t} .
$$

Selanjutnya dilakukan uji asumsi sisaan terhadap model ARIMA $(0,1,1)$ untuk kurs USD terhadap Rupiah dan model ARIMA $(2,1,2)$ untuk kurs JPY terhadap Rupiah. Pada model ARIMA $(0,1,1)$ untuk kurs USD dan ARIMA $(2,1,2)$ untuk kurs JPY pada $\alpha=10 \%$ diperoleh bahwa sisaan tidak terdapat autokorelasi, serta sisaan tidak menyebar nomal dan data bersifat homokedastisitas. 
Perbandingan Investasi Dua Mata Uang dengan ARIMA dan GARCH 5

Selanjutnya melakukan peramalan kurs USD dan JPY dengan menggunakan model terbaik.

Tabel 3. Nilai dan peramalan data kurs USD

\begin{tabular}{|l|l|l|l|l|l|l|l|}
\hline Tanggal & Peramalan & Aktual & error & Tanggal & Peramalan & Aktual & error \\
\hline 22 Juni 2016 & 12754,53 & 13232 & 477,47 & 12 Juli 2016 & 12835,08 & 13085 & 249.92 \\
\hline 23 Juni 2016 & 12793,61 & 13199 & 405,39 & 13 Juli 2016 & 12839,69 & 13030 & 190.31 \\
\hline 24 Juni 2016 & 12798,21 & 13230 & 431,79 & 14 Juli 2016 & 12844,3 & 13023 & 178.70 \\
\hline 27 Juni 2016 & 12802,82 & 13428 & 625,18 & 15 Juli 2016 & 12848,91 & 13021 & 172.09 \\
\hline 28 Juni 2016 & 12807,43 & 13190 & 382,57 & 18 Juli 2016 & 12853,52 & 13046 & 192.48 \\
\hline 29 Juni 2016 & 12812,04 & 13100 & 287,96 & 19 Juli 2016 & 12858,13 & 13021 & 162.87 \\
\hline 30 Juni 2016 & 12816,65 & 13114 & 297,35 & 20 Juli 2016 & 12862,74 & 13034 & 171.26 \\
\hline 01 Juli 2016 & 12821,26 & 13106 & 284,74 & 21 Juli 2016 & 12867,34 & 13056 & 188.66 \\
\hline 04 Juli 2016 & 12825,87 & 13106 & 280,13 & 23 Juli 2016 & 12871,95 & 13036 & 164.05 \\
\hline 11 Juli 2016 & 12830,48 & 13046 & 215,52 & 25 Juli 2016 & 12931,23 & 13069 & 137.77 \\
\hline
\end{tabular}

Tabel 4. Nilai dan peramalan data kurs JPY

\begin{tabular}{|c|c|c|c|c|c|c|c|}
\hline Tanggal & Peramalan & Aktual & error & Tanggal & Peramalan & Aktual & error \\
\hline 22 Juni 2016 & 121,89 & 126,68 & 4,79 & 12 Juli 2016 & 122,89 & 127,01 & 4.12 \\
\hline 23 Juni 2016 & 122,84 & 126,08 & 3,24 & 13 Juli 2016 & 122,9 & 125,16 & 2.26 \\
\hline 24 Juni 2016 & 122,83 & 127,70 & 4,87 & 14 Juli 2016 & 122,9 & 124,67 & 1.77 \\
\hline 27 Juni 2016 & 122,84 & 132,00 & 9,16 & 15 Juli 2016 & 122,91 & 122,63 & 0.28 \\
\hline 28 Juni 2016 & 122,85 & 129,29 & 6,44 & 18 Juli 2016 & 122,92 & 123,54 & 0.62 \\
\hline 29 Juni 2016 & 122,86 & 127,82 & 4,96 & 19 Juli 2016 & 122,93 & 123,00 & 0.07 \\
\hline 30 Juni 2016 & 122,86 & 127,62 & 4,76 & 20 Juli 2016 & 122,94 & 122,92 & 0.02 \\
\hline 01 Juli 2016 & 122,87 & 127,29 & 4,42 & 21 Juli 2016 & 122,94 & 121,86 & 1.08 \\
\hline 04 Juli 2016 & 122,88 & 127,29 & 4,41 & 23 Juli 2016 & 122,95 & 123,09 & 0.14 \\
\hline 11 Juli 2016 & 122,88 & 129,63 & 6,75 & 25 Juli 2016 & 122,97 & 122,68 & 0.29 \\
\hline
\end{tabular}

(2) Pemodelan kurs USD dan JPY dengan model GARCH

Langkah pertama yang harus dilakukan yaitu menghitung data return, data return yang telah dihitung kemudian diplot dengan gambar sebagai berikut

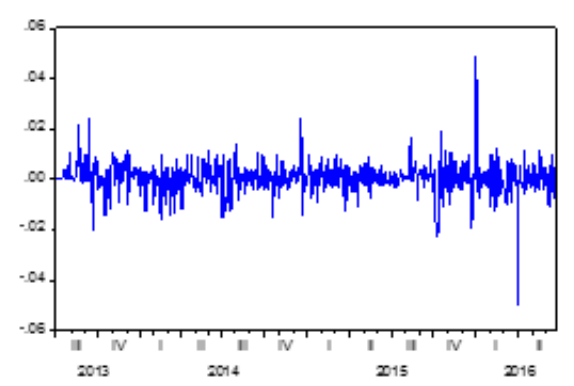

Gambar 9. Data return kurs USD

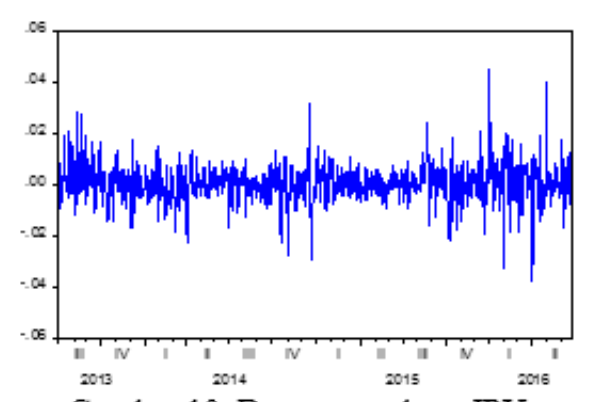

Gambar 10. Data return kurs JPY

Pada kedua plot data return terlihat bahwa return JPY memiliki fluktuasi yang lebih besar daripada return USD, meskipun demikian kedua plot data 
return berfluktuasi disekitar garis nol sehingga data telah stasioner terhadap nilai tengah. Namun pada kedua plot terdapat ketidakseragaman ragam dan tidak ada pola tren, karena itu model konstanta cukup untuk digunakan sebagai model rataan bagi return.

Model Rataan kurs Dolar Amerika (USD) dan kurs Yen Jepang (JPY) terhadap Rupiah yaitu:

(a) Kurs Dolar Amerika (USD) terhadap Rupiah $r_{t}=0.000418+\varepsilon_{t}$.

(b) Kurs Yen Jepang (JPY) terhadap Rupiah $r_{t}=0.000235+\varepsilon_{t}$.

Selanjutnya dilakukan pemeriksaan apakah terdapat pengaruh ARCH pada sisaan dengan melakukan uji ARCH-LM (Lagrange Multiplier). Pada Uji ARCH-LM diperoleh bahwa nilai-p chi-squre adalah sebesar 0.0960 untuk model rataan kurs Dolar Amerika (USD) terhadap Rupiah dan nilai-p chisquare adalah sebesar 0.0688 untuk model rataan kurs Yen Jepang (JPY) terhadap Rupiah yang nilai nya lebih kecil dari $\alpha=10 \%$ yang menunjukkan bahwa ada pengaruh ARCH pada sisan model.

Selanjutnya akan diidentifikasi orde dari model GARCH. Kemungkinan model GARCH yang diperoleh yaitu GARCH (1,1), GARCH $(2,1)$, dan GARCH $(1,2)$. Kemudian diestimasi model-model yang telah diperoleh diatas dengan rangkuman sebagai berikut.

Tabel 5. Estimasi model GARCH untuk Kurs USD terhadap Rupiah

\begin{tabular}{cccc}
\hline Model & GARCH $(1,1)$ & GARCH $(2,1)$ & GARCH $(1,2)$ \\
\hline $\mathrm{C}$ & $5.88 \times 10^{-6}(0.0000)$ & $5.13 \times 10^{-6}(0.0000)$ & $6.4 \times 10^{-6}(0.0000)$ \\
\hline$\alpha_{1}$ & $0.257559(0.0000)$ & $0.281136(0.0000)$ & $0.349902(0.0000)$ \\
\hline$\alpha_{2}$ & - & - & $-0.310528(0.0000)$ \\
\hline$\beta_{1}$ & $0.640485(0.0000)$ & $0.282259(0.0002)$ & $0.949772(0.0000)$ \\
\hline$\beta_{2}$ & - & $0.354178(0.0003)$ & - \\
\hline AIC & -7.426757 & -7.434327 & -7.455380 \\
\hline BIC & -7.401535 & -7.402800 & -7.423853 \\
\hline log Likelihood & 2707.339 & 2711.095 & Ada koefisien negatif pada $\alpha_{2}$ \\
\hline Peringkat & 2 & 1 & GARCH $(2,1)$ \\
\hline \multicolumn{7}{c}{ Tabel 6. Estimasi model GARCH untuk Kurs JPY } & terhadap Rupiah \\
\hline Model & GARCH $(1,1)$ & GARCH $(1,2)$ & $5.84 \times 10^{-6}(0.0218)$ \\
\hline c & $8.72 \times 10^{-6}(0.0024)$ & $1.01 \times 10^{-6}(0.0110)$ & $0.123304(0.0002)$ \\
\hline$\alpha_{1}$ & $0.052660(0.0000)$ & $0.064912(0.0038)$ & $-0.076564(0.0166)$ \\
\hline$\alpha_{2}$ & - & - & $0.946758(0.0000)$ \\
\hline$\beta_{1}$ & $0.936331(0.0000)$ & $0.700595(0.0699)$ & - \\
\hline$\beta_{2}$ & - & $0.222015(0.5438)$ & -6.882777 \\
\hline AIC & -6.881826 & -6.879778 & -6.851250 \\
\hline BIC & -6.856605 & -6.848252 & 2510.331 \\
\hline log Likelihood & 2508.985 & 2509.239 & pada $\alpha_{2}$ \\
\hline Peringkat & 1 & Tidak signifikan pada & Ada koefisien yang negatif \\
\hline
\end{tabular}

Berdasarkan hasil estimasi Tabel 5 dan Tabel 6 diperoleh: 
(a) Kurs Dolar Amerika (USD) terhadap Rupiah:

$r_{t}=0.000756+\varepsilon_{t}$, dengan $\sigma_{t}^{2}=0.00000513+0.28113 \epsilon_{t-1}^{2}+0.282259 \sigma_{t-1}^{2}+$ $0.354178 \sigma_{t-1}^{2}$.

(b) Kurs Yen Jepang (JPY) terhadap Rupiah:

$r_{t}=0.000235+\varepsilon_{t}$, dengan $\sigma_{t}^{2}=0.000000872+0.052660 \epsilon_{t-1}^{2}+$ $0.936331 \sigma_{t-1}^{2}$.

Setelah didapatkan model terbaik diatas dilakukan uji asumsi sisaan untuk model terbaik hasil estimasi yaitu GARCH $(2,1)$ untuk kurs USD terhadap Rupiah dan GARCH $(1,1)$ untuk kurs JPY terhadap Rupiah. Pada model GARCH $(2,1)$ untuk kurs USD dan GARCH $(1,1)$ untuk kurs JPY pada $\alpha=10 \%$ diperoleh bahwa sisaan tidak terdapat autokorelasi, serta sisaan tidak menyebar nomal dan data bersifat homokedastisitas.

Setelah itu dilakukan peramalan volatiltas dan perhitungan Value at Risk dengan hasil seperti pada Tabel 7.

Tabel 7. Nilai Ramalan Ragam dan volatilitas kurs USD terhadap Rupiah

\begin{tabular}{|c|c|c|l|}
\hline Tanggal & Ramalan Return & Ramalan Volatilitas & VaR USD \\
\hline 22 Juni 2016 & 0.000756 & 0.005833 & 3369.55 \\
\hline 23 Juni 2016 & 0.000756 & 0.006552 & 3831.74 \\
\hline 24 Juni 2016 & 0.000756 & 0.006432 & 3754.57 \\
\hline 27 Juni 2016 & 0.000756 & 0.006607 & 3866.76 \\
\hline 28 Juni 2016 & 0.000756 & 0.006662 & 3902.13 \\
\hline 29 Juni 2016 & 0.000756 & 0.006752 & 3960.46 \\
\hline 30 Juni 2016 & 0.000756 & 0.006822 & 4005.18 \\
\hline 01 Juli 2016 & 0.000756 & 0.006892 & 4050.33 \\
\hline 04 Juli 2016 & 0.000756 & 0.006956 & 4091.04 \\
\hline 11 Juli 2016 & 0.000756 & 0.007016 & 4129.48 \\
\hline 12 Juli 2016 & 0.000756 & 0.007071 & 4165.13 \\
\hline 13 Juli 2016 & 0.000756 & 0.007123 & 4198.46 \\
\hline 14 Juli 2016 & 0.000756 & 0.007171 & 4229.55 \\
\hline 15 Juli 2016 & 0.000756 & 0.007217 & 4258.60 \\
\hline 18 Juli 2016 & 0.000756 & 0.007259 & 4285.74 \\
\hline 19 Juli 2016 & 0.000756 & 0.007298 & 4311.12 \\
\hline 20 Juli 2016 & 0.000756 & 0.007335 & 4334.85 \\
\hline 21 Juli 2016 & 0.000756 & 0.007370 & 4357.05 \\
\hline 23 Juli 2016 & 0.000756 & 0.007402 & 4377.83 \\
\hline 25 Juli 2016 & 0.000756 & 0.007432 & 4397.28 \\
\hline
\end{tabular}


Tabel 8. Nilai Ramalan Ragam dan Volatilitas untuk JPY terhadap Rupiah

\begin{tabular}{|c|c|c|c|}
\hline Tanggal & Ramalan Return & Ramalan Volatilitas & VaR JPY \\
\hline 22 Juni 2016 & 0.000234 & 0.008494 & 5340.61 \\
\hline 23 Juni 2016 & 0.000234 & 0.008499 & 5343.56 \\
\hline 24 Juni 2016 & 0.000234 & 0.008503 & 5346.48 \\
\hline 27 Juni 2016 & 0.000234 & 0.008508 & 5349.36 \\
\hline 28 Juni 2016 & 0.000234 & 0.008512 & 5352.21 \\
\hline 29 Juni 2016 & 0.000234 & 0.008516 & 5355.02 \\
\hline 30 Juni 2016 & 0.000234 & 0.008521 & 5357.80 \\
\hline 01 Juli 2016 & 0.000234 & 0.008525 & 5360.55 \\
\hline 04 Juli 2016 & 0.000234 & 0.008529 & 5363.27 \\
\hline 11 Juli 2016 & 0.000234 & 0.008534 & 5365.96 \\
\hline 12 Juli 2016 & 0.000234 & 0.008538 & 5368.62 \\
\hline 13 Juli 2016 & 0.000234 & 0.008542 & 5371.24 \\
\hline 14 Juli 2016 & 0.000234 & 0.008546 & 5373.84 \\
\hline 15 Juli 2016 & 0.000234 & 0.008550 & 5376.40 \\
\hline 18 Juli 2016 & 0.000234 & 0.008554 & 5378.94 \\
\hline 19 Juli 2016 & 0.000234 & 0.008558 & 5381.45 \\
\hline 20 Juli 2016 & 0.000234 & 0.008562 & 5383.93 \\
\hline 21 Juli 2016 & 0.000234 & 0.008566 & 5386.38 \\
\hline 23 Juli 2016 & 0.000234 & 0.008570 & 5388.80 \\
\hline 25 Juli 2016 & 0.000234 & 0.008573 & 5391.19 \\
\hline
\end{tabular}

Dari Tabel 8 terlihat bahwa nilai ramalan return terlihat stabil, sedangkan untuk ramalan volatiltas terlihat bahwa semakin lama volatilitas semakin besar sehingga nilai VaR juga semakin besar.

\section{Kesimpulan}

Model Arima terbaik untuk kurs USD adalah ARIMA $(0,1,1)$ dan GARCH terbaik adalah GARCH $(2,1)$. Sedangkan model ARIMA terbaik untuk kurs JPY adalah ARIMA $(2,1,2)$ dengan GARCH terbaik GARCH $(1,1)$. Dari peramalan ARIMA terbesar dan VaR terkecil diperoleh investasi terbaik antara kurs USD dan kurs JPY yaitu kurs USD.

\section{Daftar Pustaka}

[1] Brockwell, P.J. dan R.A. Davis. 2002. Introduction to Time Series and Forecasting. Springer, New York.

[2] Tsay, R.S. 2002. Analysis of Financial Time Series. John Wiley \& Sons, Inc, New Jersey.

[3] Wei, W.S. 2006. Time Series Analysis : Univariate and Multivariate Methods. Pearson, Boston. 